\title{
ANÀLISI DE L'ESPECIFICITAT MORFOLÒGICA I SEMÀNTICA DE LA NEOLOGIA ANDORRANA
}

\section{ANALYSIS OF THE MORPHOLOGICAL AND SEMANTIC SPECIFITITY OF THE ANDORRAN NEOLOGY}

\author{
Rafael Muñoz-Espí / Carolina Bastida-Serra \\ Universitat de València / Universitat d'Andorra \\ rafael.munoz@uv.es / cbastida@uda.ad
}

Resum: L'estudi de la neologia és important no sols des d'un punt de vista metalingüístic, sinó també des de la perspectiva de la planificació lingüística, ja que mitjançant la monitorització de la creació lèxica és possible fer noves propostes lexicogràfiques i terminològiques. Donada la singularitat d'Andorra dins del domini lingüístic català, tant en termes demogràfics i geogràfics com polítics i culturals, la llengua pot tenir necessitats lèxiques i terminològiques diferents de la d'altres territoris. En aquest treball s'han analitzat els patrons de morfologia i dels processos de formació de la neologia andorrana, tot comparant-los amb els de la resta del domini lingüístic. A més, s'han classificat i analitzat semànticament els neologismes específics (anomenats hàpaxs) andorrans i s'ha observat que la creació lèxica específica ve determinada en general per l'entorn social, cultural, polític i econòmic d'Andorra.

Paraules clau: neologia, hàpax, Andorra, terminologia.

Abstract: The study of neology is not only important from a metalinguistic point of view, but also from the perspective of language planning, because monitoring the lexical creation allows for new lexicographic and terminological proposals. Taking into account the singularity of Andorra within the Catalan language domain, in terms of demography and geography but also regarding politics and culture, the language can have lexicographic and terminological needs that are different from other territories. This work analyzes the patterns in morphology and formation processes of the Andorran neology, comparing them with the rest of the language domain. Furthermore, the Andorran specific neologisms (so-called hapax legomena) have been classified and analyzed semantically, which has led to the observation that specific lexical creation is determined by the social, cultural, political, and economic environment of Andorra. 
Rafael Muñoz-Espí \& Carolina Bastida-Serra

Anàlisi de l'especificitat morfològica i semàntica de la neologia andorrana

Key words: neology, hapax legomenon, Andorra, terminology.

\section{$\operatorname{cosectats}$}

\section{INTRODUCCIÓ}

A la nostra cuina sempre n'hi ha hagut, de carn i de peix. Avui, però, al món globalitzat de casa nostra també tenim kebab i sashimi. De missatges se n'han escrit d'ençà que el català és llengua, i sempre s'han escoltat discursos orals. Avui, però, també enviem SMS i retuitegem piulades amb el corresponent hashtag —o amb la corresponent etiqueta, com recomana el TERMCAT — mitjançant la nostra tauleta; i escoltem els últims podcasts amb el reproductor d'MP3, o directament amb l'smartphone, que ara s'hauria de dir telèfon intel.ligent. El món canvia, i també ho fan les llengües per tal d'adaptar-se als canvis socials, culturals i econòmics. Potser fins i tot les llengües mortes canvien, ja que la Viquipèdia té la seua versió en llatí, Vicipaedia. I qui sap si al Vaticà, potser algun secretari, per avisar el seu company que ja ha enviat el correu electrònic que volia, dirà: «Misi iam epistulam electronicam». Bé, això no ho sabem..., però el que sí que sabem és que la nostra llengua canvia i només així és capaç de sobreviure. Com diu M. Teresa Cabré (2004: 19), artífex de l'Observatori de Neologia (OBNEO) i actual presidenta de la Secció Filològica de l'IEC, «qualsevol llengua viva i amb voluntat de continuar sent-ho ha de ser creativa fins i tot amb el risc de desfigurar parcialment la seva genuïnitat».

De l'estudi de les novetats que apareixen en una llengua — tant si són lèxiques com morfològiques, fonètiques, semàntiques o sintàctiques — se n'encarrega la neologia, una disciplina relativament jove dins de la lingüística. ${ }^{1}$ Més enllà de l'interès estrictament filològic per a l'anàlisi del sistema lingüístic, l'estudi de la neologia és important des d'un punt de vista terminològic i lexicogràfic, però també sota la perspectiva de la política i la planificació lingüístiques. D’una banda, és important analitzar les noves paraules — $\mathrm{O}$, en general, les noves unitats lèxiques_ — i les freqüències respectives per tal de monitoritzar l'evolució de la llengua i incorporar als nous diccionaris o reculls terminològics els nous mots i els nous significats. I d'altra banda, hem de tenir en

I. Cal indicar que alguns lingüistes reserven el terme neologia per a la novetat lèxica o semàntica, però no el fan servir per a les novetats sintàctiques o morfològiques (vegeu, per exemple, Ginebra 20I5). 
compte que la neologia no ocorre sols de forma espontània, sinó que pot ser també planificada, per tal de cobrir les noves necessitats lèxiques o per tal d'adaptar manlleus neològics.

L'estudi de la neologia catalana ha experimentat un avanç molt significatiu en les últimes dècades, d'ençà de la creació de l'OBNEO a Barcelona el I988 i la incorporació de noves tecnologies a la lingüística aplicada. L'activitat de l'OBNEO va començar a donar els seus fruits al cap d'uns anys i es van fer els primers estudis quantitatius sobre neologia en català (Obsevatori de Neologia 1998). Paral-lelament, el TERMCAT — creat el 1985 per l'Institut d'Estudis Catalans i la Generalitat de Catalunya - s'ha encarregat de la realització de tasques terminològiques que han involucrat necessàriament una neologia planificada, com ho demostra que el $1997 \mathrm{i}$ el 200I es publicaren el Diccionari de neologismes i el Nou diccionari de neologismes, respectivament (López del Castillo 200I). Avui dia, el TERMCAT posa els neologismes tècnics i científics normalitzats en català a l'abast dels usuaris de manera electrònica a través de l'anomenada Neoloteca. ${ }^{2}$ Les tasques terminològiques del TERMCAT i d'observació i descripció de la neologia de l'OBNEO han estat complementàries.

Al llarg dels últims anys s'han anat publicant diversos treballs sobre creació lèxica, que s'han centrat en els processos de formació (per exemple: Feliu et alii 2002 [2008]; Vallès 2002 [2008] i 2004; Observatori de Neologia 2004a; Estopà Bagot 20IO; Cabré et alii 20I4; Creus \& Julià-Muné 20I5), en la categoria gramatical dels neologismes (per exemple els verbs: Bernal 2007 i 2008; Blanco Ruiz 2012) o en àrees temàtiques específiques (per exemple les noves tecnologies: Mas 2003; o els colors: Domènech \& Estopà 20I5a). És especialment destacable que la colossal Gramàtica del català contemporani, obra eminentment descriptiva, contingui seccions específiques sobre neologismes quan tracta de morfologia i creació lèxica (Cabré 2002 [2008]a i 2002 [2008]b). A banda dels estudis realitzats a partir del buidatge de la premsa escrita (per exemple: Observatori de Neologia 1998; Estopà 20IO), s’han analitzat també de manera quantitativa buidatges neològics de textos orals de ràdio i televisió (Domènech et alii 2002 [2008], Domènech \& Estopà 2009).

Per tal d'estudiar la variació geogràtica de la neologia (és a dir, la neologia diatòpica), l'OBNEO va promoure la creació d'una xarxa d'observatoris de neologia que va rebre el nom de NEOXOC i que va començar les seues activitats el 2008. La xarxa compta amb vuit observatoris de neologia a vuit universitats arreu de l'àmbit català: la Universitat d'Alacant, la Universitat d'Andorra, la Universitat Pompeu Fabra (Barcelona), la Universitat de les Illes Balears (Palma), la Universitat de Girona, la

2. En línia a <http://www.termcat.cat/neoloteca>.

Caplletra 66 (Primavera, 2019), p. 85-112 
Universitat de Lleida, la Universitat de Perpinyà Via Domícia i la Universitat Rovira i Virgili (Tarragona). Els primers resultats obtinguts per aquesta xarxas' han anat publicant en els darrers anys (Domènech \& Estopà 20II i 20I5; Ginebra \& Rull 20I3; Cabré et alii 20I4). Malgrat que Andorra ha estat tractada en aquests estudis sobre la variació diatòpica de la neologia, fins al moment s'ha investigat molt poc si les peculiaritats en termes culturals, econòmics i sociolingüístics del Principat tenen un efecte en una o altra direcció en els processos de formació de neologismes. Només s'ha publicat un sol estudi específic sobre la neologia andorrana, i dedicat exclusivament als manlleus del castellà (Bastida Serra 2009).

El present treball s'ha plantejat per a analitzar l'especificitat de la neologia andorrana d'una manera més detallada i global. Hem analitzat els neologismes a la premsa escrita andorrana per tal d'esbrinar la freqüència dels neologismes exclusius (o hàpaxs) d'Andorra en relació amb els neologismes que també es documenten en altres regions. S'han analitzat també els patrons de morfologia i dels processos de formació de la neologia andorrana, tot comparant-los amb els de la resta del domini lingüístic català, per veure si hi ha diferències. Finalment, s'han classificat i analitzat semànticament els neologismes hàpaxs andorrans partint de la hipòtesi que l'aparició de neologismes específics ha de tenir a veure amb elements extralingüístics de l'entorn social, cultural i polític andorrà. Donada la singularitat d'Andorra dins del domini lingüístic català, tant en termes demogràfics i geogràfics com polítics i culturals, la llengua pot tenir unes necessitats lèxiques i terminològiques diferents a la d'altres regions.

\section{METODOLOGIA}

En aquest treball s'ha realitzat una anàlisi quantitativa dels neologismes apareguts a la premsa andorrana en català en el període 20072015 , complementada amb una valoració qualitativa de les dades. Els neologismes analitzats al treball són, específicament, aquells que apareixen recollits a la base de dades de l'Observatori de Neologia (BOBNEO) de l'Institut Universitari de Lingüística Aplicada (IULA) de la Universitat Pompeu Fabra, consultables a través d'una plataforma electrònica (Cabré $\&$ Estopà 2009). ${ }^{3}$ Cadascun dels observatoris o nodes de la xarxa NEOXOC s'encarrega

3. La base de dades de l'OBNEO (BOBNEO) es pot consultar a través de dues vies d'accés: la plataforma OBNEO (<http://obneo.iula.upf.edu/pobneo/>) i el cercador OBNEO (<http://obneo.iula.upf.edu/bobneo/>). L'accés a través de la primera, que ofereix més opcions, està disponible només per a usuaris registrats introductors de neologismes als diferents nodes. La segona via d'accés és oberta a qualsevol usuari i només permet la consulta. 
del buidatge neològic de fonts de l'àrea geogràfica corresponent. Tot i que al node de Barcelona es realitza també el buidatge de fonts orals (ràdio i televisió), a Andorra el buidatge és exclusiu de premsa escrita, de manera que en aquest treball ens limitem als mitjans escrits. Les cinc fonts de buidatge andorranes al llarg dels anys de treball de la xarxa NEOXOC han estat les següents:

(i) Diari Bondia Andorra (des de 2007 fins a l'actualitat)

(ii) Diari d'Andorra (des de 2007 fins a febrer de 20I5, data en què va deixar de buidar-se, ja que després que el mitjà esdevinguera de pagament només se'n buidaven els titulars i els extractes gratuïts)

(iii) El Periodic d'Andorra (des de 2007 fins a l'actualitat)

(iv) ARA Andorra (des de febrer de 2015 fins a l'actualitat)

(v) Fòrum (des de febrer de 2015 fins a l'actualitat)

El buidatge es realitza sobretot a partir de les versions digitals dels periòdics de manera semiautomatizada, però també es fa de manera més esporàdica un buidatge manual en paper (d'uns Ioo neologismes per any), que permet trobar neologismes semàntics (per exemple: nevada, amb el sentit 'pluja de vots en blanc') i sintagmàtics (per exemple: balança fiscal, banda ampla, bombolla immobiliària), que el programa de detecció automàtica BUSCANEO no pot detectar (Cabré et alii 2004: 290).

Per a fer els còmputs de neologismes s'han considerat totes les entrades validades de la base de dades (fins al 20I5, inclòs). El nombre de lemes de la base de dades de l'OBNEO en el moment de tancar els recomptes (última revisió: 9 de gener de 20I6) era de 58 I 94 lemes (sense repeticions, però tenint en compte que formes ortogràłiques diferents de la mateixa unitat representen lemes diferents) per a tots els nodes i de 3388 neologismes per al node d'Andorra (tenint en compte només entrades de diaris i revistes i no resultats de buidatges orals). El nombre d'entrades totals (amb repetició de lemes) era de 167320 de manera global a la base de dades i de 6655 per a Andorra.

\section{I CRITERI LEXICOGRÀFIC PER A LA DETECCIÓ DE NEOLOGISMES}

Tenint en compte que la «novetat» és un concepte relatiu, la definició de neologisme no és trivial i depèn del criteri que s' utilitze per a la categorització. El criteri utilitzat per l'OBNEO i la xarxa NEOXOC —i, per tant, en aquest treball— és l'anomenat criteri lexicogràfic, segons el qual és neologisme qualsevol unitat que no aparega en uns diccionaris determinats, que constitueixen el corpus d'exclusió. Els observatoris 
Rafael Muñoz-Espí \& Carolina Bastida-Serra

Anàlisi de l'especificitat morfològica i semàntica de la neologia andorrana

de neologia de la xarxa NEOXOC utilitzen com a corpus d'exclusió el Diccionari de la llengua catalana de l'IEC [DIEC], el Gran diccionari de la llengua catalana d'Enciclopèdia Catalana $[G D L C]$ i la Gran Enciclopèdia Catalana. Qualsevol paraula o unitat lèxica que no aparega en aquests diccionaris serà considerada neològica, encara que ja hi hagués constància anterior de la paraula i que pogués estar inclosa en altres diccionaris. Una de les limitacions d'aquest criteri és que arcaismes — diametralment oposats per definició als neologismes - que no apareixen en cap d'aquestes tres fonts són considerats com a unitats neològiques. ${ }^{4}$ No obstant això, el criteri lexicogràfic és tècnicament el més convenient $\mathrm{i}$, en paraules de Cabré (Observatori de Neologia 2004b: 38), és també «el més objectivable».

\subsection{CONCEPTE D’HÀPAX EN NEOLOGIA DIATÒPICA}

Aquest treball analitza els neologismes (seguint el criteri lexicogràfic exposat) que apareixen al node d'Andorra de la base de dades de l'OBNEO, fent una èmfasi especial en aquells que són exclusius i que no apareixen en altres nodes del domini lingüístic. Aquests neologismes exclusius d'una àrea geogràfica determinada reben el nom de neologismes hàpaxs o simplement hàpaxs. La categorització d'un neologisme com a hàpax propi d'Andorra indica que apareix exclusivament amb aquesta marca geogràfica a la base de dades, però no exclou necessàriament que puga també haver estat utilitzat en altres textos escrits o en discursos orals produïts fora d'Andorra i que no han estat objecte de buidatge. El nombre d'ocurrències d'un hàpax ve determinat pel nombre d'entrades registrades a la base de dades amb aquest lema.

4. Des de l'OBNEO i la xarxa NEOXOC s'és plenament conscient d'aquesta problemàtica. És per això que, com indiquen Domènech i Estopà (2014: 8), a NEOXOC «per a cada neologisme detectat s'anota amb una marca explícita el fet que aparegui documentat en una de les obres següents: el Diccionari català-valencià-balear, d'Alcover-Moll, i el Vocabulari específic rossellonès amb traducció en francès i en català normatiu, de Renat Botet." 
Rafael Muñoz-Espí \& Carolina Bastida-Serra Anàlisi de l'especificitat morfològica i semàntica de la neologia andorrana

\section{ANÀLISI MORFOLÒGICA I DELS PROCESSOS DE FORMACIÓ EN LA NEOLOGIA DE LA PREMSA ANDORRANA}

\section{I COMPARACIÓ DIATÒPICA DELS PROCESSOS DE FORMACIÓ DE NEOLOGISMES}

El node d'Andorra recollia amb data de 9 de gener de 2016 un total de 3388 neologismes a la base de dades de l'OBNEO, amb un nombre de 6655 ocurrències. D'aquests neologismes, 777 els hem identificat com a hàpaxs propis del node $(22,9 \%$ del total de neologismes). La neologia general és espontània i sol ser efímera (Observatori de Neologia 2004b: 3I), la qual cosa explica per què una part molt considerable dels hàpaxs només tenen una ocurrència. Dels 777 hàpaxs, 686 (al voltant d'un $88 \%$ ) tenen una única ocurrència registrada a la base de dades de l'OBNEO, 57 es repeteixen dues vegades (al voltant d'un $7 \%$ ), 24 (5\%) tenen entre 3 i 5 ocurrències i només 9 (al voltant de l'ı \%) es repeteixen 6 o més vegades. Aquestes dades són indicatives del possible caràcter passatger de bona part dels neologismes.

En primer lloc, s'ha analitzat la distribució de neologismes segons els processos de formació (taula I). Sovint els autors que estudien la neologia consideren típicament la prefixació com el procés de formació de mots més productiu en llengua catalana (Observatori de Neologia 2004b: 48; Domènech \& Estopà 20I5b; Ginebra \& Rull 20I3). Ara bé, això és només cert si es consideren per separat els manlleus en distintes llengües. Altrament, considerats en conjunt, els estrangerismes ocupen la primera posició dels recursos de formació. A Andorra, representen el $28,2 \%$ de tots els neologismes, proporció relativament semblant a la situació global a tots els territoris $(21,5 \%$ de manlleus respecte del total de lemes neològics). Els processos de prefixació (20,7\% a Andorra i $14,5 \%$ globalment) i sufixació ( $17,5 \%$ a Andorra i $13,4 \%$ globalment) ocupen la segona i la tercera posició, respectivament, i van seguits per la composició culta (I $4,4 \%$ a Andorra i Io, $0 \%$ globalment). 
Rafael Muñoz-Espí \& Carolina Bastida-Serra

Anàlisi de l'especificitat morfològica i semàntica de la neologia andorrana

\begin{tabular}{|c|c|c|c|c|}
\hline \multirow{2}{*}{ Procediment de formació } & \multicolumn{2}{|c|}{ Neologismes al node d'Andorra } & \multicolumn{2}{|c|}{ Hàpaxs } \\
\hline & Lemes & $\%$ & Lemes & $\%$ \\
\hline I. Manlleus de totes les llengües (adaptats o no) & 954 & 28,2 & 184 & 23,7 \\
\hline Anglès & 549 & $(57,5)^{[a]}$ & 102 & $(55,4)^{[a]}$ \\
\hline Castellà & 237 & $(24,8)^{[a]}$ & 44 & $(23,9)^{[a]}$ \\
\hline Francès & 66 & $(6,9)^{[a]}$ & $I 2$ & $(6,5)^{[a]}$ \\
\hline Italià & 22 & $(2,3)^{[a]}$ & 5 & $(2,7)^{[a]}$ \\
\hline Altres llengües & 80 & $(8,5)^{[a]}$ & $2 I$ & $(I I, 5)^{[a]}$ \\
\hline 2. Prefixació & 703 & 20,7 & I4I & $\mathrm{I} 8, \mathrm{I}$ \\
\hline 3. Sufixació & 592 & 17,5 & II4 & $\mathrm{I} 4,7$ \\
\hline 4. Composició culta & 488 & $\mathrm{I} 4,4$ & 153 & 19,7 \\
\hline 5. Variació & 167 & 4,9 & $8 \mathrm{I}$ & $\mathrm{IO}, 4$ \\
\hline 6. Sintagmació & I39 & $4, \mathrm{I}$ & 27 & 3,5 \\
\hline 7. Composició patrimonial & 100 & 3,0 & 39 & 5,0 \\
\hline 8. Neologismes semàntics & $8 \mathrm{I}$ & 2,4 & $\mathrm{I} 2$ & 1,5 \\
\hline 9. Conversió & 55 & I,6 & 4 & 0,5 \\
\hline Io. Truncació (abreviació, acronímia i siglació) & 48 & $\mathrm{I}, 4$ & 15 & $\mathrm{I}, 9$ \\
\hline II. Prefixació + sufixació & 25 & 0,7 & 3 & 0,4 \\
\hline I2. Lexicalització & 22 & 0,6 & I & $\mathrm{O}, \mathrm{I}$ \\
\hline 13. Neologismes sintàctics & 5 & O,I & I & $\mathrm{O}, \mathrm{I}$ \\
\hline I4. Altres processos de formació & 9 & 0,3 & 2 & 0,3 \\
\hline Total & $34 \mathrm{I} 4$ & IOO,O & 777 & 100,0 \\
\hline
\end{tabular}

[a] Percentatge respecte del total de manlleus

Taula I. Distribució dels neologismes de la premsa andorrana continguts a l'OBNEO segons el procediment de formació.

Quan comparem els processos de formació dels hàpaxs amb els neologismes del node d'Andorra en general, les tendències són semblants, però cal indicar que la composició culta sobrepassa la prefixació i ocupa la segona posició, cosa que no ocorre quan considerem el conjunt de lemes (hàpaxs i no hàpaxs). De manera semblant, la composició patrimonial en hàpaxs sembla tenir una productivitat neològica lleugerament més alta $(5,0 \%)$ que la sintagmació $(3,5 \%)$, mentre que en el conjunt de neologismes andorrans l'ordre és invers (3,0\% per a la composició patrimonial i 4,I \% per a la sintagmació). La figura I presenta de manera gràfica els percentatges dels distints processos de formació d'hàpaxs neològics a Andorra. 


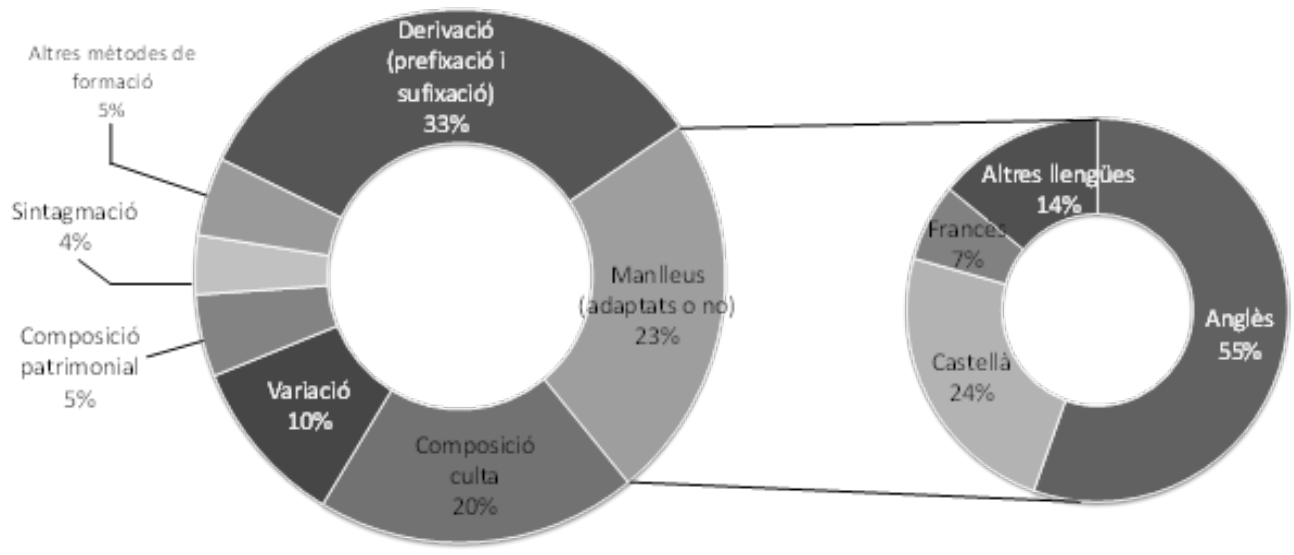

Figura I. Percentatges dels processos de formació en hàpaxs andorrans (l'etiqueta «altres mètodes de formació» inclou els punts 8 a I4 de la taula I).

Veiem a continuació alguns exemples destacables d'hàpaxs andorrans originats pels distints processos de formació:

(a) Manlleus de l'anglès adaptats: bàtxelor, boardercros, brifing, esquijòrer, telemarc

(b) Manlleus de l'anglès no adaptats: combi-race, cross-country, food court, freeski, jibbing

(c) Manlleus del francès no adaptats: huissier, musette, non-lieu, postier

(d) Manlleus del castellà adaptats: albedriu, astiller, bocanada, enganxe

(e) Manlleus del castellà no adaptats: berrinche, besamanos, maremoto, telearrastre

(f) Altres manlleus adaptats: ippon (japonès), atopos (grec), ristreto (italià)

(g) Altres manlleus no adaptats: jugendstil (alemany), arcoballeno (italià), cursus (llatí)

(b) Prefixació: antijaume, antiparadisos, coprincesa, interparroquial, multiactivitats, multitemporada

(i) Sufixació: andorranisme, andorranitat, andorranitzar, bartumeuisme, cinquisme, parroquialisme, tonimartinisme

(j) Composició culta: andorranocatalà-ana, andorranocentrisme, autoblanqueig, cibergendarmes, termolúdic

(k) Variació: aventatge, discució, esllevisada

(l) Sintagmació: camp de neu, esqui de muntanya, parc hoteler 
Rafael Muñoz-Espí \& Carolina Bastida-Serra

Anàlisi de l'especificitat morfològica i semàntica de la neologia andorrana

(m) Composició patrimonial: activitat-espectacle, arquebisbe-bisbe, atac-i-gol, iglú-hotel

(n) Neologismes semàntics: clípol ('autobús interurbà anomenat d'acord amb el nom d'una empresa'), nevada ('pluja de vots en blanc')

(o) Conversió: parapública

(p) Acronímia: biblioestiu, clownclusió, estanflació, funitel

(q) Prefixació + sufixació: acarreronar

(r) Lexicalització: preconvocat

En un estudi sobre la neologia diatòpica, Domènech i Estopà (2015b) fan una comparació dels distints processos de formació de neologismes als distints territoris utilitzant dades de la xarxa NEOXOC per al període 200820 . tuats en el present treball (vegeu figura 2), actualitzats fins a l'any 2015, no difereixen substancialment dels obtinguts per aquestes autores per a anys anteriors. Podem constatar que Andorra segueix patrons de formació força semblants a la resta de territoris. El gràfic fa palesa alguna singularitat destacable al node de Lleida (sufixació menys productiva que a la resta de territoris, percentatge de manlleus de l'anglès significativament superior, formació per variació molt baixa). A més a més, tant per al node de Perpinyà com per al node de Barcelona els cinc processos representats queden en conjunt per sota del $50 \%$ mentre que a la resta de territoris es troben clarament per sobre)..$^{5}$ Seria interessant d'intentar esbrinar els motius d'aquestes particularitats, però l'anàlisi de les dades d'aquests nodes queda fora de l'abast d'aquest estudi.

5. En el cas concret de Perpinyà, val a dir que només hi ha registrats $40 \mathrm{O}$ neologismes, ja que es va discontinuar el buidatge. Amb tan poques paraules és arriscat treure conclusions sobre tendències de formació. De fet, estudis recents de neologia de la xarxa NEOXOC (Cabré et alii 20I4) deixen fora el node de Perpinyà per aquest motiu. 


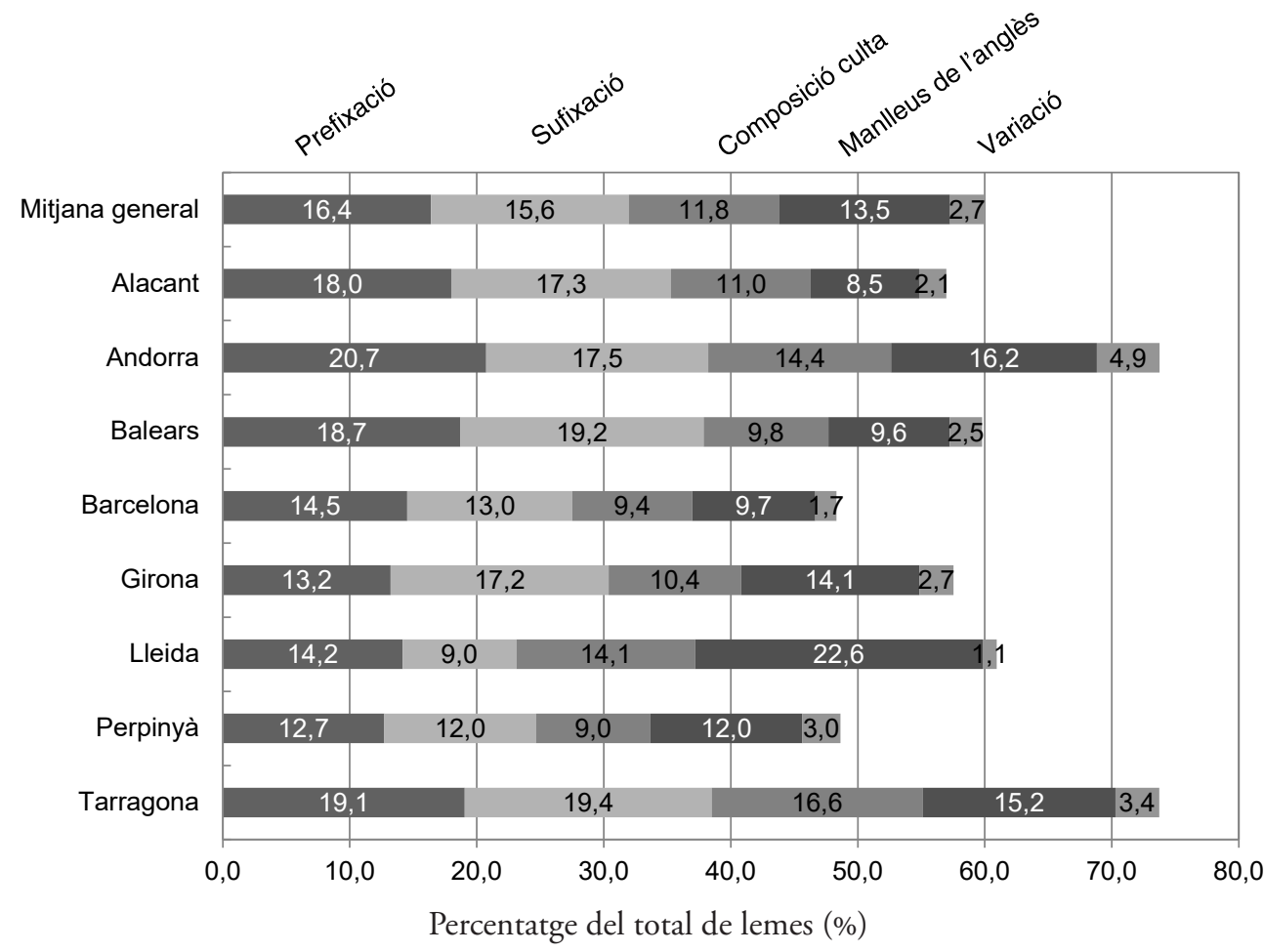

Figura 2. Comparació als distints territoris de la distribució percentual dels cinc processos de formació de neologismes més productius a Andorra (prefixació, sufixació, composició culta, manlleus de l'anglès i variació).

\subsection{NEOLOGIA FORMADA PER MANLLEU}

Com hem vist més amunt, la formació de neologia a partir de manlleus és a hores d'ara la més prolífica en llengua catalana, també en la premsa andorrana i en els hàpaxs propis d'aquest node. L'observació més evident és que l'anglès és de lluny la llengua més productiva en la formació de neologismes a la premsa andorrana: més de la meitat $(57,5 \%)$ dels neologismes formats per manlleu provenen d'aquesta llengua. Aquesta tendència reprodueix els resultats trobats en altres contextos, com ara en les emissions televisives de Catalunya (Creus \& Julià-Muné 2015), en què la modalitat lingüística emprada sol ser menys planificada i editada que no pas aquella de la premsa escrita. Segueix el castellà ( $24,8 \%$ de tots els manlleus hàpaxs) i, ja de lluny, en tercera posició, el francès (amb un 6,9\%). La formació d'hàpaxs a partir d'altres 
Rafael Muñoz-Espí \& Carolina Bastida-Serra

Anàlisi de l'especificitat morfològica i semàntica de la neologia andorrana

llengües (llatí, italià, alemany, grec, japonès...) és esporàdica i genera només pocs lemes. Especialment en el cas d'aquests neologismes formats en llengües diferents de les majoritàries (anglès, castellà i francès), es fa sovint difícil d'esbrinar per què aquests mots són precisament hàpaxs d'Andorra i no de cap altre territori. Per exemple: per què apareixen només entrades provinents d'Andorra per a neologismes com atopos (adaptat del grec), ristreto (adaptat de l'italià), khaleeji (de l'àrab), kibbut (de l'hebreu), mudra (del sànscrit), jugendstil(del'alemany), arcoballeno (de l'italià) o cursus (del llatí)? També resulta curiosa l'aparició d'alguns hàpaxs andorrans provinents del japonès: kabucki (teatre japonès), hentai (tipus de còmic eròtic) o els termes relacionats amb les arts marcials —alguns amb un nombre infreqüentment alt d'ocurrències-ippon (3 ocurrències), kumite (19 ocurrències!), mawashi, yuko o harai-goshi. De manera general, podem dir que l'aparició d'aquests hàpaxs de llengües estrangeres sembla més aviat fruit de la casualitat que no pas d'una «especificitat andorrana» o de qüestions pragmàtiques del context andorrà.

Durant l'estudi dels neologismes per manlleu a Andorra se'ns va plantejar la qüestió de si hi havia diferències geogràfiques significatives amb els altres territoris, $o$ bé pel que fa a la productivitat de la neologia per manlleu, o bé pel que fa la distribució dels neologismes segons les llengües d'origen. Les dades de la comparació diatòpica per als distints nodes es presenten a la taula 2.

\begin{tabular}{|c|c|c|c|c|c|c|c|c|}
\hline \multirow[t]{2}{*}{ Node } & \multicolumn{2}{|c|}{$\begin{array}{c}\text { Manlleus de } \\
\text { totes les llengües }\end{array}$} & \multicolumn{2}{|c|}{$\begin{array}{c}\text { Manlleus de } \\
\text { l'anglès }\end{array}$} & \multicolumn{2}{|c|}{$\begin{array}{l}\text { Manlleus del } \\
\text { castellà }\end{array}$} & \multicolumn{2}{|c|}{$\begin{array}{l}\text { Manlleus del } \\
\text { francès }\end{array}$} \\
\hline & Lemes & $\%^{[a]}$ & Lemes & $\%^{[b]}$ & Lemes & $\%^{[b]}$ & Lemes & $\%^{[b]}$ \\
\hline Alacant & 2703 & 19,7 & II 75 & 43,5 & 557 & 20,6 & 295 & 10,9 \\
\hline Andorra & 954 & 28,2 & 549 & 57,5 & 237 & 24,8 & 66 & 6,9 \\
\hline Balears & 750 & 25,5 & $28 \mathrm{I}$ & 37,5 & 327 & 43,6 & 34 & 4,5 \\
\hline Barcelona & 9382 & $2 \mathrm{I}, 8$ & $4 \mathrm{I} 68$ & 44,4 & 2574 & 27,4 & 716 & 7,6 \\
\hline Girona & I 380 & 26,8 & 724 & 52,5 & 303 & 22,0 & IO4 & 7,5 \\
\hline Lleida & 782 & 37,7 & 470 & $60, \mathrm{I}$ & 159 & 20,3 & 54 & 6,9 \\
\hline Perpinyà & $\mathrm{I} 23$ & 30,7 & 48 & 39,0 & 6 & 4,9 & 57 & 46,3 \\
\hline Tarragona & $44 \mathrm{I}$ & 27,6 & 242 & 54,9 & $\mathrm{I} 28$ & 29,0 & 22 & 5,0 \\
\hline
\end{tabular}

[a] Percentatge respecte del total de neologismes del node (Andorra: 3388, Alacant: 13743, Barcelona: 42 995, Balears: 2942, Girona: 5153, Lleida: 2076 , Perpinyà: 40I, Tarragona: I 595).

[b] Percentatge respecte del total de manlleus del node.

Taula 2. Comparació de l'ocurrència de manlleus del castellà, de l'anglès i del francès als distints nodes de la base de dades de l'OBNEO. 
Malgrat que, a causa de la relació històrica amb França, podríem potser esperar que el francès tingués a Andorra un grau de productivitat de neologismes més elevat que a altres territoris, les dades obtingudes ens indiquen que, amb un $6,9 \%$, la proporció de manlleus del francès és semblant a la d'altres regions del domini lingüístic. Fins i tot a Alacant els gal.licismes són més abundants en neologismes (I0,9\% del total de manlleus) que a Andorra. Només a Perpinyà, com d'altra banda seria esperable, el francès és predominant.

En comparació amb Barcelona (44,4\%) o Alacant $(43,5 \%)$, per exemple, la proporció de neologismes provinents de l'anglès és més de io punts superior a Andorra ( $57,5 \%$ de tots els neologismes), però també Girona, Tarragona o Lleida tenen percentatges semblants i superiors al $50 \%$, la qual cosa relativitza la significació d'aquesta dada. Una vegada més sembla que és Lleida —amb gairebé un $40 \%$ de neologismes formats per manlleu- i no pas Andorra el node que presenta particularitats que haurien de ser estudiades.

Pel que fa a l'adaptació o no dels manlleus, hem analitzat l'anglès com a cas paradigmàtic, ja que aquesta llengua és la primera en formació de neologismes. La tendència a l'adaptació dels manlleus anglesos a Andorra (amb un 9,7\%) és superior que a la resta de territoris (p. ex. Alacant: 5,0\%, Barcelona: 6,3\%, Girona: 6,8\%), amb excepció de les Illes Balears (amb un curiós I4,2\%) i Perpinyà (I0,4\%).

\subsection{NEOLOGIA FORMADA PER PREFIXACIÓ, SUFIXACIÓ I COMPOSICIÓ CULTA}

En aquest apartat analitzem la formació d'hàpaxs, com a casos més representatius de la neologia andorrana, per processos de derivació (prefixació i sufixació) i composició culta. La taula 3 mostra els formants més productius en la producció d'hàpaxs $\mathrm{i}$ compara els percentatges per al node d'Andorra amb els generals per a tots els nodes.

De manera coincident amb la tendència global en català, el prefix anti- és el més productiu en la formació d'hàpaxs a Andorra. En canvi, el prefix re-, que en el conjunt de nodes ocupa la segona posició, passa a una posició més baixa en el rànquing d'hàpaxs andorrans. El segon prefix més productiu és pre-, que ocupa la tercera posició globalment en català. Els prefixos multi-, semi-, sub-i des-, que segueixen anti- i pre-, també tenen una productivitat alta d'hàpaxs ( 8 o més lemes), malgrat que en l'àmbit global de tot el domini lingüístic els percentatges corresponents a la formació de neologismes amb aquests prefixos són —amb l'excepció de des_— clarament més baixos.

A diferència de la prefixació, els hàpaxs formats per sufixació presenten diferències menys significatives respecte de la tendència global del català. Els sufixos més produc- 
tius a Andorra en hàpaxs, -isme, -dor, -ista (nom o adjectiu), -itat i itzar, encapçalen també la llista global de tots els territoris per al conjunt de neologismes en català.

D’altra banda, vuit dels nou formants més productius (més de 4 lemes) en la formació d'hàpaxs per composició culta es troben també en la "llista dels deu primers» de tot el domini. No obstant això, hi ha dos formants concrets amb incidència a Andorra i molt poc productius a la resta de territoris, andorrano- (p. ex. andorranocatalà -ana, andorranoespanyol -a, andorranofilia, andorranocentrisme) i proto- (protoespia, protopartit, protofeminista, prototurisme). Les raons de la rellevància d'andorrano- per a Andorra i de per què aquest formant és poc productiu a altres territoris són òbvies i no requereixen explicacions. De fet, totes les entrades amb aquest formant a la base de dades de l'OBNEO són d'Andorra, com també havien observat ja anteriorment Ginebra et alii (20I4). El cas de proto-, en canvi, és si més no interessant, ja que no hi ha cap motiu aparent pel qual aquest formant haja de ser més productiu en un territori que en un altre. 
Rafael Muñoz-Espí \& Carolina Bastida-Serra Anàlisi de l'especificitat morfològica i semàntica de la neologia andorrana

\begin{tabular}{|c|c|c|c|c|c|}
\hline \multirow[t]{2}{*}{ Tipus de formant } & \multirow[t]{2}{*}{ Formant } & \multicolumn{2}{|c|}{$\begin{array}{l}\text { Hàpaxs al node } \\
\text { d'Andorra }\end{array}$} & \multicolumn{2}{|c|}{$\begin{array}{l}\text { General (lemes a partir del } \\
\text { formant a tots els nodes) }\end{array}$} \\
\hline & & Nombre & $\%$ & Lemes & $\%$ \\
\hline \multirow{11}{*}{ Prefix } & anti- & 19 & $\mathrm{I} 3,2$ & II 83 & $\mathrm{I} 3,7$ \\
\hline & pre- & I4 & 9,7 & 473 & 5,5 \\
\hline & multi- & IO & 6,9 & 266 & $3, \mathrm{I}$ \\
\hline & semi- & 8 & 5,6 & 299 & 3,5 \\
\hline & sub- & 8 & 5,6 & 225 & 2,6 \\
\hline & des- & 8 & 5,6 & $44 \mathrm{I}$ & $5, \mathrm{I}$ \\
\hline & pseudo- & 7 & 4,9 & 239 & 2,8 \\
\hline & hiper- & 6 & 4,2 & I75 & 2,0 \\
\hline & $\mathrm{CO}^{-}$ & 6 & 4,2 & 258 & 3,0 \\
\hline & inter- & 6 & 4,2 & 190 & 2,2 \\
\hline & ultra- & 6 & 4,2 & 196 & 2,3 \\
\hline \multirow{10}{*}{ Sufix } & -isme & 16 & 13,7 & 696 & 8,7 \\
\hline & -dor & I3 & II,I & 240 & 3,0 \\
\hline & -ista (n. o adj.) & $\mathrm{I} 3$ & II,I & II68 & $\mathrm{I} 4,6$ \\
\hline & -itat & 8 & 6,8 & 389 & 4,9 \\
\hline & -itzar & 8 & 6,8 & 357 & 4,5 \\
\hline & -able & 6 & $5, \mathrm{I}$ & 250 & $3, \mathrm{I}$ \\
\hline & -atge & 5 & 4,3 & 6I & 0,8 \\
\hline & -eig & 4 & 3,4 & 35 & 0,4 \\
\hline & -ístic, -ística & 4 & 3,4 & IOI & $\mathrm{I}, 3$ \\
\hline & -ià, -iana & 4 & 3,4 & 504 & 6,3 \\
\hline \multirow{9}{*}{ Formant culte } & auto- & I6 & 13,7 & $67 I$ & II, 5 \\
\hline & eco- & II & 9,4 & 176 & 3,0 \\
\hline & micro- & 9 & 7,7 & 203 & 3,5 \\
\hline & macro- & 8 & 6,8 & 238 & $4, \mathrm{I}$ \\
\hline & andorrano- & 6 & $5, \mathrm{I}$ & 6 & $\mathrm{O}, \mathrm{I}$ \\
\hline & mini- & 6 & $5, \mathrm{I}$ & 260 & 4,5 \\
\hline & socio- & 6 & $5, \mathrm{I}$ & 90 & 1,5 \\
\hline & euro- & 5 & 4,3 & 206 & 3,5 \\
\hline & proto- & 4 & 3,4 & 36 & 0,6 \\
\hline
\end{tabular}

Taula 3. Formants més productius en la formació de neologismes hàpaxs a la premsa andorrana per prefixació, sufixació i composició culta. 
Rafael Muñoz-Espí \& Carolina Bastida-Serra

Anàlisi de l'especificitat morfològica i semàntica de la neologia andorrana

\subsection{NEOLOGIA FORMADA PER VARIACIÓ}

Crida l'atenció que una part no menyspreable dels neologismes considerats hàpaxs a Andorra són formats per variació (8I d'un total de 777, com hem vist a la taula I). Recordem que, segons el criteri lexicogràfic, les errades ortogràłiques són considerades com a «neologismes». De fet, la pràctica totalitat d'aquests neologismes constitueixen grafies incorrectes des d'un punt de vista normatiu de mots existents, o de vegades simplement errates (per exemple: ${ }^{*}$ absorvent, ${ }^{*}$ adecuació,${ }^{*}$ bevible, ${ }^{*}$ desinvolt, *mal.leable, *massosquisme). Es podria plantejar, doncs, la qüestió de si la neologia formada per variació a Andorra —o, dit d'altra manera, la falta de cura ortogràfica- és especialment significativa quan es compara amb la resta de territoris. Les dades de la figura 2 indicaven que un 4,9\% del total de neologismes a Andorra està format per variació, mentre que els percentatges a la resta de territoris era representativament inferior: Alacant (2,I\%), Barcelona ( $\mathrm{I}, 7 \%)$, Illes Balears $(2,5 \%)$, Girona $(2,7 \%)$, Lleida $(\mathrm{I}, \mathrm{I} \%)$, Perpinyà $(3, \mathrm{O} \%)$ i Tarragona $(3,4 \%)$. Ara bé, una cosa és el nombre de lemes (sense comptar-hi repeticions) i altra les ocurrències totals per variació. Quan considerem el nombre total d'ocurrències per al node d'Andorra, 3,0\%, veiem que no difereix tan substancialment respecte de la majoria de territoris (a Tarragona, per exemple, les ocurrències de neologismes formats per variació representen també el 3,0\%). De fet, tenint en compte la proporció lemes-ocurrències, es podria especular que, si la major part de la variació és deguda a errades, els altres territoris potser realitzen les mateixes errades de manera més sistemàtica que a Andorra, mentre que a Andorra les errades són més aleatòries o «espontànies». Cal indicar també que en analitzar les distintes fonts de buidatge del node d'Andorra (El Diari d'Andorra, el Diari Bondia i El Periòdic d'Andorra $)^{6}$ no hem pogut observar cap diferència significativa pel que fa al percentatge d'ocurrència de la variació.

\section{ANÀLISI SEMÀNTICA DELS HÀPAXS NEOLÒGICS A LA PREMSA AN- DORRANA}

Amb la finalitat de valorar la relació entre la semàntica dels neologismes hàpaxs $\mathrm{i}$ l'entorn social, cultural i polític d'Andorra, s'han classificat els neologismes hàpaxs en camps semàntics. Les fitxes dels neologismes de la base de dades de l'OBNEO inclouen

6. No s'han considerat les dues fonts que s'han començat a buidar el 20I5, ARA Andorra i Fòrum, ja que el breu espai de temps de buidatge i el nombre de lemes no ens semblaven suficientment representatius. 
la categoria gramatical i el procés de formació de les paraules, però no inclouen cap informació semàntica. Aquesta classificació s'ha de fer, doncs, de manera manual per a cadascun dels lemes. Atès que, fins on arriba el nostre coneixement, aquest és el primer intent de fer una classificació semàntica o temàtica de les dades recollides en un node de la xarxa NEOXOC, no disposem de dades comparables de la resta de nodes. Així doncs, la valoració de l'especificitat dels neologismes analitzats es basa en el concepte d'hàpax. Entenem que el fet que els neologismes analitzats apareguen de manera exclusiva a Andorra pot ser un bon indicador de les particularitats semàntiques de la neologia detectada en aquest node. En aquesta anàlisi hem intentat també una certa aproximació des de la pragmàtica, ja que hem d'analitzar factors extralingüístics —o, en altres paraules, hem de recórrer al nostre coneixement del món- per tal d'explicar l'aparició o la freqüència de certes paraules. Els resultats apareixen recollits a la figura 3 .

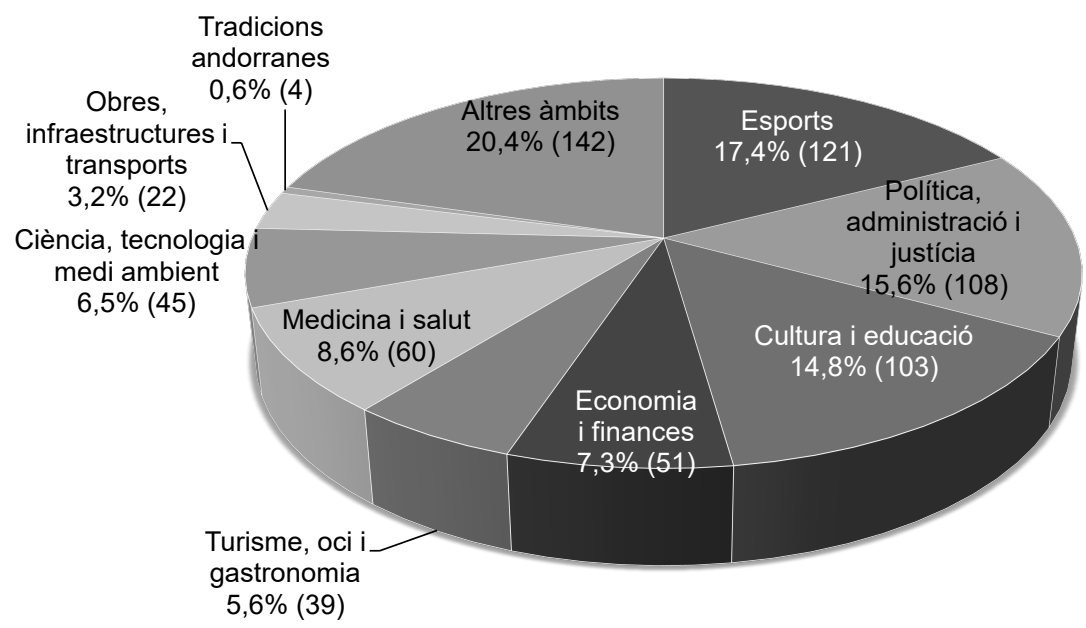

Figura 3. Distribució dels hàpaxs andorrans segons els camps semàntics (nombre d'hàpaxs de cada categoria indicat entre parèntesi).

S'ha d'indicar que en l'anàlisi semàntica vam deixar de banda la neologia per variació, ja que, com hem vist, la pràctica totalitat de neologismes representen grafies no normatives de mots existents. Considerem que la inclusió en una anàlisi semàntica de la neologia per variació podria falsejar les tendències, especialment tenint en compte el caràcter molt sovint aleatori de les errades. Dit d'una altra manera, el còmput dels neologismes formats per variació podria distorsionar la importància relativa de determinats camps semàntics. Ara bé, sí que hem considerat la variació (és a dir, dife- 
Rafael Muñoz-Espí \& Carolina Bastida-Serra

Anàlisi de l'especificitat morfològica i semàntica de la neologia andorrana

rents formes gràfiques, incloses aquelles que sembla evident que són normativament incorrectes) per als hàpaxs generats per processos de formació diferents de la variació (per exemple bàtxel.lor com a variant de bàtxelor o boardercros i boarder cros com a variants de boarder cross).

El resultat més rellevant és que, si deixem de banda el camp "Altres àmbits», els esports constitueixen el camp semàntic que més neologismes hàpaxs genera a Andorra (al voltant del $\mathrm{i} 8 \%$ ). El camp "Altres àmbits» no és de fet un camp semàntic estricte, sinó una mena de calaix de sastre on s'han inclòs els mots de difícil adscripció en altres camps. La gran majoria d'hàpaxs d'aquesta categoria (I37 d'un total de I42) tenen una única ocurrència. Així doncs, podem especular que la majoria d'aquests hàpaxs són resultat d'una neologia espontània, amb caràcter efímer i una probabilitat de repetició baixa. La suma dels camps «política», «administració» $\mathrm{i}$ «justícia i dret» té un pes percentual al voltant del $16 \%$, semblant al del camp "cultura i educació» (I5\%). La resta de camps tenen un pes substancialment menor. A continuació, discutirem cadascun dels camps i alguns dels exemples característics.

\section{(a) Esports}

Del total de I2I hàpaxs relacionats amb els esports, n'hi ha $47(39 \%)$ que tenen relació amb els anomenats esports d'hivern, la qual cosa no requereix gaire explicació tenint en compte la geografia pirinenca i la importància de la neu en l'economia del Principat. Els hàpaxs d'esports d'hivern representen el grup més gran dins del camp semàntic dels esports. D'altra banda, hi ha també un nombre no menyspreable d'hàpaxs sobre l'automobilisme i el motociclisme (per exemple: brifing, breefing, superpole, triraid), disciplines que compten amb una certa tradició a Andorra.

No és gaire estrany tampoc el nombre elevat d'hàpaxs relacionats amb el futbol i els esports de pilota (atac-i-gol, porter-jugador, ultraculer, ultramerenga, benfiquista, brasileritzar...). El que sí que crida l'atenció és la presència de 5 hàpaxs japonesos relacionats amb les arts marcials: kumite (I9 ocurrències), ippon (3), yuko (I), wazari (I), mawashi (I), als quals ja ens havíem referit a la secció 3.I.I en parlar de la formació de neologismes per manlleu. No deixa de ser sorprenent que l'hàpax esportiu amb més repeticions - i el segon hàpax, després de parapública, amb més ocurrències de tot el conjunt d'hàpaxs andorrans_- siga precisament kumite. Si considerem el conjunt de documents redactats en català només caldrà una ràpida cerca en un buscador d'Internet per a adonar-nos que aquest terme apareix també en documents no andorrans (té fins $i$ tot una entrada pròpia a la Viquipèdia catalana i ve recollit pel TERMCAT com a sinònim complementari de combat en karate). Recordem, però, una vegada més que la nostra consideració d'hàpax fa referència a les dades incloses a la base de dades de la 
xarxa NEOXOC. És molt poc probable que la quantitat de practicants d'arts marcials a Andorra siga proporcionalment més gran que a altres parts del domini lingüístic, però tenim constància que al Principat es realitzen competicions periòdiques que tenen transcendència a la premsa. El I8 de juny del 20I4, per exemple, el diari Bondia incloïa una notícia — que també contenia en el text el terme kumite— amb el titular "Rècord de participació a l'Open d'Escaldes amb 643 karatekes». ${ }^{7}$ Tenint en compte la dimensió reduïda del Principat, és molt possible que competicions d'aquest tipus tinguen suficient rellevància per a arribar a ocupar un lloc a la premsa - la qual cosa justifica també l'aparició de neologismes relacionats—, mentre que a altres àrees geogràqiques més grans i amb més població, esports dels considerats «de masses» (futbol, bàsquet, automobilisme, motociclisme) siguen prioritzats i no deixen espai per a altres de més minoritaris com les arts marcials. En qualsevol cas, tot i potser anecdòtic, el fet ens ha semblat destacable.

Per altre costat, a partir d'una anàlisi creuada dels camps semàntics i dels processos de formació de neologismes hàpaxs, s'ha observat que del total de IO2 manlleus de l'anglès, 55 es classifiquen dins del camp semàntic dels esports (la qual cosa representa al voltant d'un $54 \%$ del total de manlleus de l'anglès). Això demostra que el manlleu de l'anglès és especialment productiu en la producció de neologismes hàpaxs en esports.

\section{(b) Política, administració i justícia/dret}

Hi ha un nombre important d'hàpaxs d'aquesta categoria que molt probablement no són percebuts com a neologismes pels parlants d'Andorra, però que ho són des d'un punt de vista lexicogràfic. És el cas d'andorranitat, andorranitzar, interparroquial o parapública (en aquest darrer cas, neologisme com a substantiu).

No cal dir que aquestes unitats lèxiques, com una part important de les corresponents a aquesta àrea semàntica, estan íntimament lligades a elements propis del sistema polític i administratiu del Principat (com són, per exemple, les parròquies). Aquesta singularitat política i administrativa origina un lèxic distint a la de la resta dels territoris del domini lingüístic, que posseeixen sistemes diferents.

A més a més, hi ha un nombre d'hàpaxs de la terminologia política, com antijaume, bartumenisme, fornerià, gabrielià o tonimartinisme, que tenen a veure amb polítics andorrans contemporanis. La formació de neologismes a partir d'antropònims sembla tenir una certa productivitat en el camp semàntic de la política, si bé aquest comportament no és exclusiu d'Andorra.

7. <http://www.bondia.ad/esports/record-de-participacio-lopen-descaldes-amb-643-karatekes> (consultat: gener de 20I6).

Caplletra 66 (Primavera, 2019), p. 85-112 


\section{(c) Cultura i educació}

En aquest camp semàntic hem inclòs els hàpaxs que tenen a veure amb temes culturals en un sentit ampli, com les arts plàstiques (macroescultura, escultor-tallista, art pop), el teatre (metateatre, kabucki), el cinema (cinèfil, semidocumental, mostrahomenatge), la literatura (micropoesia, zafonmania, cafe literari, biblioestiu) o la premsa i la televisió (no-periodisme, groc-ga). L’àrea temàtica que genera més hàpaxs en aquest camp, però, és amb molta diferència la música, amb 30 lemes. Alguns exemples d'hàpaxs musicals són: beatlemaniac -a, clarinista, death core (també deathcore), demoscene, electrorock, etnoinstrumental, etnopop, funky-house, gipsy swing, liricisme, metalcore, mid-tempo, musicocultural, precàsting, silence party.

No disposem d'un argument concloent per a explicar per què Andorra té aquesta productivitat d'hàpaxs de termes musicals (formats molts d'ells a través de manlleus de l'anglès), però a la vista dels resultats es podria especular que és possible que la premsa andorrana dedique una atenció més significativa a la música que la premsa d'altres territoris del domini lingüístic.

D'hàpaxs relacionats directament amb l'educació se n'han trobat només sis, dos dels quals són variants de la mateixa paraula: bàtxel.lor, bàtxelor, collège, desescolaritzar, ludoescola ('centre d'educació per a infants en què s'empren jocs educatius, joguets, etc. $)^{8} \mathrm{i}$ nanograu. Per aquest motiu s'han inclòs també en el camp semàntic de cultura $\mathrm{i}$ no s'ha creat un camp específic. Malgrat les singularitats del sistema educatiu andorrà, no sembla que l'educació siga una àrea semàntica productiva des d'un punt de vista neològic. A la base de dades trobem dues entrades de maternal com a neologisme format per conversió (substantiu format a partir de l'adjectiu, que sí que apareix al $D I E C$ ), però només una és andorrana (l'altra és de la revista El Temps en una referència a la Catalunya del Nord), de manera que no podem considerar hàpax aquesta unitat lèxica. Relacionat amb el sistema educatiu andorrà tenim també l'hàpax esqui-estudi, que és un programa específic de l'Escola Andorrana per als alumnes de segona ensenyança i batxillerat que formen part d'equips de competició d'esquí. Els estudiants del programa combinen l'entrenament esportiu amb l'estudi. Aquest hàpax, però, l'hem classificat al camp semàntic dels esports, dins dels esports d'hivern.

El cas de bàtxelor és interessant i paga la pena de comentar-lo. A partir del procés de Bolonya sobre l'Espai Europeu d'Ensenyament Superior comencen a generalitzar-se els títols de bachelor i màster del model anglosaxó a tot Europa. De manera diferent a la gran majoria de països europeus, l'Estat espanyol es va decidir per un model educatiu amb un primer cicle de 4 anys (que passaria a anomenar-se

8. Definició del Repertori andorrà (Rull 20I4: 38). 
grau, amb una denominació ambigua i inespecífica) i un segon cicle d'i any (màster). A Andorra s'opta pel model més comú a Europa de $3+2$ anys. Per referir-se a la titulació de primer cicle s'hauria pogut escollir la denominació diplomatura, que ja existia en català amb un significat semblant, però això hauria generat problemes de diferenciació amb els títols antics de diplomats anteriors al pla de Bolonya. A més, es volia marcar clarament una diferència amb el sistema espanyol de 4 anys, de manera que grau tampoc no era una opció. Així doncs, es va triar l'adaptació ortogràfica del terme anglès i es va crear el neologisme bàtxelor. El TERMCAT inclou l'entrada al CERCATERM com a sinònim complementari de grau i afegeix una indicació que la denominació bàtxelor és pròpia d'Andorra.

(d) Tradicions andorranes

En aquest camp només hem pogut classificar quatre hàpaxs: buner, cortalà, escudellaire, enganxe. No obstant això, hem decidit mantenir-lo com a camp independent per la rellevància dins del tema del present treball. El DIEC recull buna, però no buner. Tampoc trobem aquesta paraula al $D C V B$, però és evident que no es tracta d'una paraula «nova», si més no a Andorra. ${ }^{9}$ Tampoc són noves les paraules cortalà $\mathrm{i}$ escudellaire, que ja apareixen al DCVB. Es tracta més aviat de dialectalismes que no han arribat als diccionaris generals que representen les fonts d'exclusió; però, una vegada més, d'acord amb el criteri lexicogràfic, aquests mots són considerats com a neologismes.

(e) Economia i finances

És sobradament coneguda la importància que els bancs i les institucions financeres han tingut en la història recent del Principat. Per això no és estrany que aparega algun hàpax esporàdic relacionat amb el sistema financer i fiscal d'Andorra, com autoblanqueig o antiparadisos. No obstant això, la majoria d'hàpaxs en aquest camp no tenen cap especificitat andorrana.

(f) Turisme, oci i gastronomia

Bona part dels hàpaxs d'aquesta categoria tenen vinculació amb activitats relacionades amb el turisme de muntanya (per exemple: multiactivitats, iglú-hotel, precalendari, colonista, preparc natural, parc hoteler). Els neologismes amb més ocur-

9. De forma anecdòtica sobre el caràcter no neològic del mot, podem indicar que una de les llegendes més antigues i populars del Principat d'Andorra, recollida en totes les recopilacions de llegendes del país, és precisament El buner d'Ordino. 
Rafael Muñoz-Espí \& Carolina Bastida-Serra

Anàlisi de l'especificitat morfològica i semàntica de la neologia andorrana

rències ( $6 \mathrm{i}$ 4, respectivament) són termolúdic i multiactivitats, ambdós utilitzats com a substantius. Termolúdic fa referència a les instal.lacions d'aigua mineromedicinal calenta a Escaldes-Engordany (exemple: «El nou pont d'accés a Caldea, que substituirà les actuals escales metàl-liques de l'entrada del termolúdic, serà de titularitat pública», Diari d'Andorra I4/02 2008). Tot i que com a adjectiu termolúdic no és hàpax, de les I7 entrades al la base de l'OBNEO, I6 fan referència al centre termolúdic d'Andorra, encara que el neologisme es trobe en altres territoris. Això demostra que és una paraula molt característica de la realitat andorrana.

(g) Medicina i salut

S'ha identificat un nombre molt alt d'hàpaxs (60) dins d'aquest camp, però no sembla haver-hi cap relació aparent entre els termes i aspectes propis d'Andorra. En tot cas, en alguns mots molt concrets (com multicontusió, polifractura, politraumatizar) es podria pensar en una certa relació dels termes amb el tipus d'accidents que poden produir-se durant la pràctica d'esports d'hivern, la qual cosa podria justificar l'aparició d'aquests hàpaxs a la premsa andorrana.

(b) Tecnologia i medi ambient

Els hàpaxs més tecnològics (minimissatge, nanofibra, opensource) no tenen un caràcter pròpiament andorrà, però sí que podem veure una certa vinculació amb l'entorn natural pirinenc i amb el turisme ecològic que s'hi genera en els hàpaxs més relacionats amb el medi ambient (ecoaldea, ecoconducta, ecorefugiat, supraforestal).

(i) Obres, infraestructures i transport

En aquest cas també observem una relació entre alguns dels hàpaxs de la categoria i el context andorrà. L'hàpax amb més ocurrències (4) és clípol que, segons el Repertori andorrà (Rull 20I4: 23), és un autobús interurbà el nom del qual "prové d'una empresa andorrana d'autobusos interurbans dels anys 50, 60 i 70 del segle xx, formada com a acrònim de Climent i Pol, nom i cognom respectivament dels propietaris». També trobem hàpaxs que tenen a veure amb els moviments generats contra algun projecte concret (antiaeroport).

\section{CONCLUSIONS I PERSPECTIVES}

En aquest treball s'ha fet una anàlisi de l'especificitat de la neologia andorrana en comparació amb la neologia de la resta de territoris del domini lingüístic català, 
prenent com a base principal els neologismes recopilats en el període 2007-20I5 al node d'Andorra de la xarxa NEOXOC, un conjunt d'observatoris de neologia format per vuit universitats de diferents àrees dialectals de la llengua catalana. Per qüestions pràctiques s'ha tingut només en compte la premsa escrita, i concretament els cinc diaris que constitueixen les fonts de buidatge de la xarxa NEOXOC. Si bé no podem prendre la neologia a la premsa escrita com a mirall fidedigne de la totalitat de la neologia andorrana, podem considerar que representa una bona aproximació sobre la llengua general escrita.

Les conclusions principals de l'anàlisi morfològica de la neologia a la premsa andorrana han estat les següents:

I. Dins dels neologismes recollits al node d'Andorra s'ha detectat un nombre considerable d'hàpaxs, és a dir, de mots que només es troben en aquest territori. Aquests hàpaxs representen el 22,9\% del total de neologismes d'Andorra. Aquesta proporció és un primer indicador que els mots nous que apareixen a Andorra no sempre coincideixen amb aquells que apareixen en altres nodes, sinó que mostren una certa singularitat.

2. Juntament amb el node de Lleida, Andorra és un dels nodes amb una productivitat més alta de manlleus de l'anglès. Així mateix, amb un percentatge al voltant del Io \% del total de manlleus de l'anglès adaptats, sembla que Andorra mostra una tendència a l'adaptació més gran que altres territoris, només superada per les Balears i Perpinyà (tot i que el node de Perpinyà no disposa de prou dades per a poder extreure'n conclusions).

3. Entre tots els neologismes d'Andorra, hàpaxs o no, la prefixació i la sufixació, en aquest ordre, representen els dos procediments de formació més productius després de la neologia per manlleu. En canvi, quan considerem exclusivament els hàpaxs, la composició culta supera la prefixació en productivitat i ocupa la segona posició després dels manlleus.

4. En comparació amb la tendència general, els patrons de comportament en la formació de neologismes a Andorra són semblants a la resta de territoris. Només s'observen lleugeres diferències en la prefixació i la composició culta. El prefix pre-és el més productiu en hàpaxs, la qual cosa difereix una mica de la tendència neològica general en català ( $\mathrm{d}$ 'acord amb la qual anti-i re-són els prefixos més productius). Els formants cultes més productius d'hàpaxs són andorrano- (amb ocurrències exclusivament a Andorra) i proto-, que és molt poc freqüent en l'àmbit general. 
Rafael Muñoz-Espí \& Carolina Bastida-Serra

Anàlisi de l'especificitat morfològica i semàntica de la neologia andorrana

5. La neologia per variació, relacionada majoritàriament amb errades d'escriptura, és lleugerament superior a Andorra que a altres territoris quan considerem el nombre de lemes, però és molt semblant a la mitjana general quan considerem totes les ocurrències.

Pel que fa a l'anàlisi semàntica, a partir dels resultats del treball podem extreure les conclusions següents:

I. El camp semàntic més productiu des d'un punt de vista de neologia específicament andorrana (és a dir, hàpaxs) és el dels esports, seguit de les àrees semàntiques que engloben la política, l'administració i la justícia d'una banda, i la cultura i l'educació de l'altra.

2. Dins del camp dels esports, els esports d'hivern, amb un $39 \%$ del conjunt d'hàpaxs esportius, tenen un pes especial, la qual cosa està lògicament relacionada amb la importància econòmica i cultural que tenen aquests esports a Andorra.

3. Dins del camp semàntic de la cultura i l'educació, la música és l'àrea generadora d'hàpaxs més important. Hem de suposar que la premsa andorrana dedica més atenció a la música que la premsa a la resta de territoris.

4. De manera general, hi ha molt sovint una relació entre determinats neologismes i el context cultural, social i econòmic andorrà, de manera que podem validar aquesta hipòtesi de partida.

Entre les limitacions de la metodologia utilitzada cal assenyalar que ens hem basat fonamentalment en la neologia de la premsa escrita. Per a aconseguir una perspectiva més general de la neologia andorrana escrita, i sobretot amb vistes a la creació de glossaris especialitzats específics de la realitat andorrana, proposem com a línies futures de treball el buidatge de fonts textuals addicionals (per exemple documents de l'administració andorrana o revistes especialitzades de diversos àmbits). D'altra banda, seria també desitjable que, en un futur, al node andorrà de la xarxa NEOXOC es realitzen també buidatges de fonts orals (televisió i ràdio andorrana, com es fa al node de Barcelona), ja que l'oralitat dóna una visió de la llengua més espontània que també pot ser d'interès per a l'anàlisi sociolingüística i la planificació i la política lingüístiques. Finalment, per a ampliar el coneixement sobre les especificitats semàntiques de la neologia d'Andorra, de les quals hem presentat una primera aproximació en aquest treball, caldria dur a terme una anàlisi 
semàntica dels neologismes de la resta de nodes, tot emprant criteris d'etiquetatge anàlegs als utilitzats ací.

\author{
RAFAEL MuÑoz-Espí \\ Universitat de València \\ rafael.munoz@uv.es \\ ORCID 0000-0002-8I46-2332 \\ Carolina Bastida-Serra \\ Universitat d'Andorra \\ cbastida@uda.ad \\ ORCID 0000-0003-0310-0042
}

\title{
REFERÈNCIES BIBLIOGRÀFIQUES
}

Bastida Serra, C. (2009) "Els manlleus del castellà en la neologia d'Andorra», Recull de conferències 2009 / Debats de recerca, Societat Andorrana de Ciències, Andorra, 4, p. 220 23I. [En línia a <http://publicacions.iec.cat/repository/ pdf/ooooor8o oooo 057.pdf>]

BERnAL, E. (2007) «Formació de verbs, variants morfològiques i neologismes: entre la genuïnitat i el calc», dins M. Lorente, R. Estopà, J. Freixa, J. Martí i C. Tebé (ed.), Estudis de lingüistica i de lingüistica aplicada en honor de M. Teresa Cabré Castellví. Volum II: Deixebles, Barcelona, Institut Universitari de Lingüística Aplicada, Universitat Pompeu Fabra, p. 197208.

- (2008) «Els prefixos verbalitzadors $a$ - i en-: elements per a un diccionari morfològic digital», dins D. Azorín Fernández (dir.), El diccionario como puente entre las lenguas y culturas del mundo. Actas del II Congreso Internacional de Lexicografía Hispánica, Alacant, Biblioteca Virtual Miguel de Cervantes, p. 299307. [En línia a <http://www.cervantesvirtual.com/nd/ark:/585I/ bmctq6f6> ]

Blanco Ruiz, A. (20I2) «La neologia semàntica verbal en el català actual. Anàlisi d'un corpus de dades procedents de la premsa», treball final de carrera. Barcelona, Universitat Oberta de Catalunya. [En líniaa <http://hdl.handle.net/Io6o9 I5423>]

Cabré Castellví, M. T. (2002 [2008]a) «La derivació», dins J. Solà, M. R. Lloret, J. Mascaró i M. Pérez Saldanya (dir.), Gramàtica del català contemporani, vol. I, Barcelona, Empúries, p. 73I 755. [4a ed.]

— (2002 [2008]b) «Altres sistemes de formació de mots», dins J. Solà, M. R. Lloret, J. Mascaró i M. Pérez Saldanya (dir.), Gramàtica del català contemporani, vol. I, Barcelona, Empúries, p. 889932. [4a ed.] 
Rafael Muñoz-Espí \& Carolina Bastida-Serra

Anàlisi de l'especificitat morfològica i semàntica de la neologia andorrana

- (2004) «Introducció: La importància de la neologia per al desenvolupament sostenible de la llengua catalana», dins Observatori de Neologia, Llengua catalana $i$ neologia, Barcelona, Meteora.

- (2014) «La neologia, més enllà de l'actualització de diccionaris», dins M. T. Cabré Castellví, O. Domènech Bagaria i R. Estopà Bagot (ed.) (20I4) Mots nous en català / New words in Catalan, Amsterdam, John Benjamins Publishing Company, p. I-3.

Cabré, M. T., O. Domènech, R. Estopà, J. Freixa \& E. Solé (2004) «La lexicografia i la identificació automatitzada de neologia lèxica», dins M. P. Battaner i J. DeCesaris (ed.), De lexicografia: Actes del I Symposium Internacional de Lexicografia, Barcelona, Institut Universitari de Lingüística Aplicada, Universitat Pompeu Fabra, p. 287294.

Cabré Castellví, M. T. \& R. Estopà Bagot (2009) «Trabajar en neología en un entorno integrado en línea: la estación de trabajo OBNEO», Revista de Investigación Lingüistica, I2, p. I7-38. [En línia a <http://revistas.um.es/ril/article/ viewFile/9I23I 8795I>]

Cabré Castellyí, M. T., O. Domènech Bagaria \& R. Estopà Bagot, ed. (20I4) Mots nous en català / New words in Catalan, Amsterdam, John Benjamins Publishing Company.

Creus, I. \&J. Julià-Muné (20I5) «La neologia de manlleu i de base culta en emissions televisives», Caplletra, 59, p. 197219. [En línia a <http://www.raco.cat/index. php/Caplletra/article/view/29628>]

$D C V B=$ Alcover, A. M. \& F. de B. Moll (1930 1962) Diccionari català-valencià-balear, Io vol., Palma, Editorial Moll.

DIEC = Institut d'Estudis Catalans, Diccionari de la llengua catalana (2007), Barcelona, Institut d'Estudis Catalans, Editorial 62 / Enciclopèdia Catalana; Palma, Editorial Moll; València, Edicions 3 i 4. [2a ed.]

Domènech Bagaria, O. \& R. Estopà Bagot (2009) «La neología en textos orales», Revista de Investigación Lingüistica, I2, p. 39-64.

- (20II) «La neologia per sufixació: anàlisi contrastiva entre varietats diatòpiques de la llengua catalana», Caplletra, 5I, p. 9-33. [En línia a $<$ http://www.raco.cat/index. $\mathrm{php} /$ Caplletra/article/view/263io>]

- (20I4) «Prefaci», dins M. T. Cabré Castellví, O. Domènech Bagaria i R. Estopà Bagot (ed.), Mots nous en català / New words in Catalan, Amsterdam, John Benjamins Publishing Company, p. 5-13.

- (2015a) «La resemantització com a recurs creatiu: la neologia cromàtica», Caplletra, 59, p. I5 183. [En línia a <http://www.raco.cat/index.php/Caplletra/article/ view/29 626>] 
Rafael Muñoz-Espí \& Carolina Bastida-Serra Anàlisi de l'especificitat morfològica i semàntica de la neologia andorrana

- (2015b) «Neología diatópica y planificación lingüística: NEOXOC, una apuesta por la neodiversidad», dins I. M. Alves \& E. Simóes Pereira (ed.), Neologia das Línguas Românicas, São Paulo, CAPES, Humanitas, p. Io7I I094.

Domènech Bagaria, O. R. Estopà Bagot, C. Mayoral \& M. Raymi (2002 [2008]) «La recerca en neologia oral de l'Observatori de Neologia: primers resultats», dins Observatori de Neologia, Lèxic i neologia, Barcelona, Documenta Universitaria. [2a ed.]

EstopÀ BAGOT, R. (2OIO) «La composició patrimonial en català perd representativitat. Estudi d'un corpus de neologismes de premsa i de ràdio», Estudis Romànics [Institut d'Estudis Catalans], 32, p. I25 I47.

Feliu, J., Y. Garcia \& I. Obradós (2002 [2008]) «Aspectes de composició: neologismes nom-nom», dins Observatori de Neologia, Lèxic i neologia, Barcelona, Documenta Universitaria. [2a ed.]

Ginebra, J. (20I5) «Neologia i gramàtica: entre el neologisme lèxic i el neologisme sintàctic», Caplletra, 59, p. I37 I57. [Disponible a <https://ojs.uv.es/index.php/ caplletra/article/download/6905 6815>]

Ginebra, J. \& X. Rull (20I3) «Creació lèxica en la premsa del Camp de Tarragona i les Terres de l'Ebre», dins J. Mallafrè (cur.), Jornades de la Secció Filològica de l'Institut d'Estudis Catalans a Reus: homenatge a Ramon Amigó i Anglès (20 i $2 I$ d'abril de 2012), Barcelona, Institut d'Estudis Catalans.

Ginebra, J., R. Llagostera \& X. Rull (20I4), «La composició culta», dins M. T. Cabré Castellví, O. Domènech Bagaria i R. Estopà Bagot (ed.), Mots nous en català / New words in Catalan, Amsterdam, John Benjamins Publishing Company, p. 23-40.

$G D L C=$ Gran diccionari de la llengua catalana, Barcelona, Enciclopèdia Catalana, 1998. Gran Enciclopèdia Catalana, Barcelona, Enciclopèdia Catalana, I992. [2a ed.]

LÓPEZ DEL CASTILlO, L. (200I) «El TERMCAT davant els nous reptes terminològics», Llengua i ús, 2I, p. 2I-3I.

Mas i Fossas, G. (2003) «Novetats terminològiques en les noves tecnologies», Llengua $i$ us, 26, p. 64-73.

Observatori de Neologia [OBNEO] (1998) Descripció quantitativa dels neologismes documentats durant l'any I995 a la premsa en català, Barcelona, Institut Universitari de Lingüística Aplicada, Universitat Pompeu Fabra.

- (2004a) Metodologia del treball en neologia: criteris, materials i processos, Barcelona, Institut Universitari de Lingüística Aplicada, Universitat Pompeu Fabra.

- (2004b) Llengua catalana i neologia, Barcelona, Meteora.

- BOBNEO: banc de dades de l'Observatri de Neologia. [En línia a <http://obneo.iula. upf.edu/bobneo/index.php>]

Caplletra 66 (Primavera, 2019), p. 85-112 
Rafael Muñoz-Espí \& Carolina Bastida-Serra

Anàlisi de l'especificitat morfològica i semàntica de la neologia andorrana

Rull, X. (20I4) Repertori andorrà: 300 joies del vocabulari del Principat d'Andorra, la Seu d'Urgell, Edicions Salòria.

TERMCAT, Centre de Terminologia (1997) Diccionari de neologismes, Barcelona, Editorial 62.

- (200I) Nou diccionari de neologismes, Barcelona, Editorial 62.

- Neoloteca, Barcelona, TERMCAT, Centre de Terminologia, I999 20I7. [En línia a $<$ http://www.TERMCAT.cat/neoloteca $>$ ]

VAlLès, T. (2002 [2008]) «Anàlisi cognitiva del prefix euro-», dins Observatori de Neologia, Lèxic i neologia, Barcelona, Documenta Universitaria. [2a ed.]

- (2004) La creativitat lèxica en un model basat en l'ús: una aproximació cognitiva a la neologia i a la productivitat, Barcelona, Publicacions de l'Abadia de Montserrat. 